\title{
Cognitive Decline: Not Always Alzheimer's Disease
}

\author{
Noel Lorenzo Villalba ${ }^{\mathrm{a}, *}$, Stephane Laboulbene $^{\mathrm{b}}$, Tawoufik Merzouki ${ }^{\mathrm{b}}$, Manuel Méndez Bailon ${ }^{\mathrm{c}}$, \\ Melek Kechida $^{\mathrm{d}}$, Vanessa Sigonney ${ }^{\mathrm{b}}$ and Maturin Tabue Teguo ${ }^{\mathrm{e}}$ \\ a Service de Médecine Interne, Centre Hospitalier Chrétien, Belgique \\ ${ }^{\mathrm{b}}$ Service de Médecine Interne, Centre Hospitalier Saint Cyr, France \\ ${ }^{\mathrm{c}}$ Servicio de Medicina Interna, Hospital Clinico San Carlos, Spain \\ ${ }^{\mathrm{d}}$ Service de Médecine Interne, Hôpital Universitaire Fattima Bourguiba Monastir, Tunisia \\ ${ }^{\mathrm{e}}$ Service de Gériatrie, CHU de Pointe-à-Pitre, Université des Antilles, Guadeloupe
}

Accepted 14 January 2018

\begin{abstract}
A 66-year-old woman presented with slowly progressive cognitive decline. MRI showed bi-frontotemporal atrophy, but the 14.3.3 protein was not present in cerebrospinal fluid. Electroencephalogram was irrelevant. Interview with relatives led doctors to search for a genetic cause and confirmed the diagnosis of Gerstmann-Sträussler-Scheinker syndrome.
\end{abstract}

Keywords: Cognitive decline, Gerstmann-Sträussler-Scheinker syndrome, prion protein

\section{INTRODUCTION}

Human transmissible spongiform encephalopathy includes classic Creutzfeldt-Jakob disease and its variant form: Gerstmann-Straussler-Scheinker syndrome (GSS), fatal familial insomnia, and kuru [1]. GSS is an autosomal dominant disorder associated to prion protein $(\mathrm{PrP})$ gene (PRNP) mutations. The disease is often seen between the 4th and 6th decades of life [2].

\section{CASE}

A 66-year-old woman was referred to the hospital by her primary doctor to evaluate a clinical picture consistent with depression, cognitive decline, and weight loss. No relevant past medical history was disclosed. Upon arrival at the emergency department, the patient was agitated, presented with visual and

\footnotetext{
*Correspondence to: Dr. Noel Lorenzo Villalba, Service de Médecine Interne, Centre Hospitalier Chrétien, 6 Rue du Parlement, Liege, Belgique. Tel.: +33629383092; E-mail: noelloren zo@gmail.com.
}

auditory hallucinations, and stated her intention to commit suicide but that she was not able to do it. She was transferred to Internal Medicine.

On examination, the patient looked ill and body mass index was 19. Her blood pressure and heart rate were normal, with absence of murmurs. Lungs were clear and the abdominal examination was normal. Her speech was explosive. Cranial nerve testing and cerebellar tests were normal. Deep tendon reflex response was normal, and no pathological reflex response was observed. No extrapyramidal signs were found. However, she had difficulties standing in the absence of muscle atrophy.

The battery of neuropsychological tests included the Free and Cued Selective Reminding Test, the Trail-Making Test, and the Mini-Mental State Examination. These neuropsychological assessments revealed dysexecutive and attention disorders as well as an instrumental level of language disorders and difficulties in constructive praxis. On memory map, the three information processing levels were efficient but the presence of many perseverations was pathological. The patient presented an association of cognitive and psycho-behavioral disorders having a major 
impact on autonomy. During the examination, the patient revealed she had previously recognized she had problems remembering words. In consequence, she stated she planned all the activities in advance.

The results of blood studies, including chemistry panel, liver, thyroid, and renal function tests, were normal. Folic acid and vitamin B12 were within the normal range. Serology for syphilis, HIV, HBV, HCV, EBV, CMV, and herpes simplex came back negative. Protein electrophoresis was normal. Brain CT showed cortico-subcortical atrophy. Frontobitemporal atrophy was relevant on MRI scans. A lumbar puncture was performed but 14-3-3 protein was not present in the cerebrospinal fluid (CSF). We were not able to determine tau and p-tau protein in the CSF. Electroencephalography (EEG) performed during admission showed non-specific findings.

The interview with the patient's relatives, not seen until then, disclosed the patient's mother and brother died from a similar and unknown condition and that her cousin had recently developed and died from a neurological genetic condition. They just confirmed a progressive cognitive decline in the patient after the death of her husband. The suspicion of a genetic condition such as GSS syndrome was raised. The neurology department from the hospital where her relative was evaluated was contacted. They confirmed the patient died from GSS and they agreed with us to conduct genetic studies in our patient.

Effectively, PRPN analysis revealed a 189 bp insertion in the coding region of the octapeptide. This finding is identical to that described in subjects with a family affection (HDL-1) adjacent to CreutzfeldtJakob disease and GSS. In this setting, closer relatives were sent for genetic studies but the results are still not available.

\section{DISCUSSION}

Typical clinical presentation of GSS is slowly progressive cerebellar ataxia beginning in the fifth or six decade, accompanied by cognitive decline that appears at some time during the course of the illness. GSS involves a long period of illness ranging from 3 months to 13 years [3]. The diagnosis of this condition is difficult considering its rarity. The exact incidence is unknown but it is estimated between 1 and 10 per 100 million. Cerebellar symptoms or ataxia are usually present early in course the disease. Conversely, it was not the case in our patient. The patient did not present with cerebellar signs but with gait troubles and falls. She was unable to carry out daily life activities which led to a malnutrition state. This clinical condition was not assumed in the context of a true dementia.

In our patient, MRI revealed fronto-bitemporal atrophy even though several reports have indicated that MRI scans are normal during the early stage of GSS with normal cerebellar findings being common in GSS patients [4], However this exam, even if not recommended by the World Health Organization, could be quite useful for differentiating patients presenting cerebellar symptoms from those suffering from any kind of cerebellar ataxia. It was recently reported that that diffusion-weighted images can help in early diagnosis but it was not available in our hospital.

CSF testing for the 14-3-3 protein may also be of help but not conclusive. Our patient tested negative for 14-3-3 protein and had non-specific EEG changes, contrary to what have been reported in the literature. The EUROCID collaborative surveillance project found nearly $50 \%$ of cases were positive for the 14-3-3 protein in CSF, and EEG tests showed typical pseudoperiodic activity in only 2 of $26 \%$ patients [5].

The death of the patient's mother and brother of an unknown disease and the recent death of her cousin from a similar degenerative neurological condition was the cornerstone in the diagnosis of our patient.

In general, the definitive diagnosis of prion disease requires a brain biopsy or an autopsy with immunohistologic and genetic studies.

\section{CONCLUSION}

This is a case of GSS not presenting with the typical clinical picture of slowly progressive cerebellar ataxia. Genetic testing must be recommended in immediate relatives at risk who do not yet have symptoms of the disease, if the mutation is known.

\section{CONFLICT OF INTEREST}

The authors have no conflict of interest to report.

\section{REFERENCES}

[1] Prusiner SB (2001) Shattuck lecture-neurodegenerative diseases and prions. N Engl J Med 344, 1516-1526.

[2] Deters KD, Risacher SL, Yoder KK, Oblak AL, Deters KD, Risacher SL, Yoder KK, Oblak AL (2016) [(11)C]PiB PET in Gerstmann-Sträussler-Scheinker disease. Am J Nucl Med Mol Imaging 6, 84-93. 
[3] Gerstmann J, Sträussler E, Scheinker I (1936) Uber eine eigenartige hereditar-familiare Erkrankung des Zentralnervensystems. Zugleich ein Beitrag zur Frage des vorzeitigen lokalen Alterns. Z Neurol 154, 736-762.

[4] Arata H, Takashima H, Hirano R, Tomimitsu H, Machigashira $\mathrm{K}$, Izumi $\mathrm{K}$, Kikuno $\mathrm{M}, \mathrm{Ng} \mathrm{AR}$, Umehara $\mathrm{F}$, Arisato T, Ohkubo R, Nakabeppu Y, Nakajo M, Osame M, Arimura K (2006) Early clinical signs and imaging findings in Gerstmann-Sträussler-Scheinker syndrome (Pro102Leu). Neurology 66, 1672-1678.
[5] Kovács GG, Puopolo M, Ladogana A, Pocchiari M, Budka H, van Duijn C, Collins SJ, Boyd A, Giulivi A, Coulthart M, Delasnerie-Laupretre N, Brandel JP, Zerr I, Kretzschmar HA, de Pedro-Cuesta J, Calero-Lara M, Glatzel M, Aguzzi A, Bishop M, Knight R, Belay G, Will R, Mitrova E; EUROCJD (2005) Genetic prion disease: The EUROCJD experience. Hum Genet 118, 166-174. 